\title{
$B D N F$ val66met polymorphism influences age differences in microstructure of the corpus callosum
}

\author{
Kristen M. Kennedy ${ }^{1}$, Karen M. Rodrigue ${ }^{1}$, Susan J. Land ${ }^{2}$ and Naftali Raz ${ }^{3 *}$ \\ 1 Center for Brain Health, School of Behavioral and Brain Sciences, The University of Texas at Dallas, Dallas, TX, USA \\ 2 Department of Obstetrics and Gynecology, Wayne State University, Detroit, MI, USA \\ ${ }^{3}$ Department of Psychology, Institute of Gerontology, Wayne State University, Detroit, MI, USA
}

\section{Edited by:}

William J. Jagust, University of

California Berkeley, USA

Reviewed by:

Edith V. Sullivan, Stanford University

Medical School, USA

Lars Nyberg, Umea University,

Sweden

\section{*Correspondence}

Naftali Raz, Institute of Gerontology, Wayne State University, 87 E Ferry St, 226 Knapp Bldg, Detroit, MI

48202, USA.

e-mail:nraz@wayne.edu
Brain-derived neurotrophic factor (BDNF) plays an important role in neuroplasticity and promotes axonal growth, but its secretion, regulated by a BDNFgene, declines with age. The low-activity (met) allele of common polymorphism BDNFval66met is associated with reduced production of BDNF. We examined whether age-related reduction in the integrity of cerebral white matter (WM) depends on the BDNF val66met genotype. Forty-one middle-aged and older adults participated in the study. Regional WM integrity was assessed by fractional anisotropy (FA) computed from manually drawn regions of interest in the genu and splenium of the corpus callosum on diffusion tensor imaging scans. After controlling for effects of sex and hypertension, we found that only the BDNF 66met carriers displayed age-related declines in the splenium FA, whereas no age-related declines were shown by BDNF val homozygotes. No genotyperelated differences were observed in the genu of the corpus callosum. This finding is consistent with a view that genetic risk for reduced BDNF affects posterior regions that otherwise are considered relatively insensitive to normal aging. Those individuals with a genetic predisposition for decreased BDNF expression may not be able to fully benefit from BDNF-based plasticity and repair mechanisms.

Keywords: brain, diffusion tensor imaging, genetics, MRI, white matter, aging, brain-derived neurotrophic factor, single nucleotide polymorphism

\section{INTRODUCTION}

Cerebral white matter (WM) changes throughout the lifespan. Its volume increases from childhood to young adulthood, remains stable during middle age, and shrinks in senescence (Pfefferbaum et al., 1994; Bartzokis, 2004; Hasan et al., 2008; Raz and Kennedy, 2009). In late adulthood, WM accumulates pathological changes (de Leeuw et al., 2001), and the myelin sheath exhibits structural defects (Peters, 2002). Deterioration of the WM leads to loss of orientation differences in water diffusivity, reflected on diffusion tensor imaging (DTI) (Pierpaoli and Basser, 1996). DTI studies of normal aging show that the microstructural integrity of WM is also reduced with age, with a greater difference observed in anterior than posterior regions (Pfefferbaum, et al., 2000, 2005; O'Sullivan et al., 2001; Sullivan et al., 2001; Head et al., 2004; Salat et al., 2005; Sullivan and Pfefferbaum, 2006; Ardekani et al., 2007; Kochunov et al., 2007; Madden et al., 2007; Hugenschmidt et al., 2008; Stadlbauer et al., 2008; Kennedy and Raz, in press). The mechanisms of these differences are not entirely understood, but are believed to reflect cerebrovascular properties of the WM and are partly under genetic control. Notably, the regions of the brain that are late to myelinate (Flechsig, 1901) may be most vulnerable to the effects of normal aging (Bartzokis, 2004; Raz, 2004). Frontal regions for example develop relatively late (Sowell et al., 1999) and show greater influence of environmental than genetic factors in comparison to the posterior regions. Specifically, the proportion of genetic to environmental contributions to fractional anisotropy (FA) is estimated as 3:1 for the splenium but only 1:1 for the genu of the corpus callosum (Pfefferbaum et al., 2001; Sullivan and Pfefferbaum, 2006).

Because WM is malleable and its bulk reflects a dynamic equilibrium of growth and decline, age differences in the WM structure may stem from alteration in mechanisms that are responsible for maintaining that equilibrium. One potentially important factor in this process is brain-derived neurotrophic factor (BDNF). BDNF is a multipurpose protein that plays important roles in many events, including neuronal differentiation, proliferation of dendritic arbor, synaptic plasticity, and, most notably for the topic of this report, axonal sprouting (Egan et al., 2003; Binder and Scharfman, 2004). In addition, BDNF has metabotropic effects (Lebrun et al., 2006), and is protective against ischemia (Yanamoto et al., 2004; Nomura et al., 2005; Schäbitz et al., 2007; Mochizuki et al., 2008). Thus, adequate BDNF activity may be critical for maintaining WM integrity.

Brain-derived neurotrophic factor production declines with age (Sohrabji and Lewis, 2006) and is reduced by age-dependent vascular risk factors such as hypertension (Lee et al., 2006), hypoperfusion (Irikura et al., 1996), and poor glucose metabolism (Krabbe et al., 2007). Although experimental study of BDNF effects on brain aging is hampered by impossibility to manipulate human BDNF levels in vivo, natural occurring 'mendelian randomization' (Katan, 1986) of individuals into groups by BDNF availability presents an opportunity for an inquiry into BDNF effects. These natural groups are determined by a variant in the gene that controls BDNF production, $B D N F$ val66met. The low-activity met 
allele of that polymorphism is linked to reduced volume of the hippocampus (Pezawas et al., 2004; Szeszko et al., 2005; Bueller et al., 2006; Chepenik et al., 2009), parahippocampal (Takahashi et al., 2008) and prefrontal (Pezawas et al., 2004; Nemoto et al., 2006; Takahashi et al., 2008) cortices but not of the amygdala (Sublette et al., 2008). Carriers of BDNF 66met also evidence suboptimal cognitive performance (e.g., Egan et al., 2003; Bath and Lee, 2006; Miyajima et al., 2008; Raz et al., 2009). However, to the best of our knowledge, there are no reports of BDNF effects on the WM microintegrity in a healthy aging population. In addition, although there is evidence of exacerbation of BDNF val66met by vascular risk (e.g., Raz et al., 2009), little is known of such conjoint effects on brain structure.

In this study we asses the influence of $B D N F$ val66met genotype and vascular risk on the microstructural integrity of the genu and the splenium of the corpus callosum. In a limited-scale study, the densely myelinated corpus callosum (Lamantia and Rakic, 1990) is an excellent candidate region to explore effects of genetic factors on the WM. Moreover, the genu and the splenium are well suited for a comparison as WM microintegrity declines more with age in the former than in the latter (Sullivan and Pfefferbaum, 2006; Raz and Kennedy, 2009). We hypothesized that older participants and individuals with hypertension would evidence reduced FA in both regions, and that carriers of the BDNF 66met allele would show additional reduction in FA. We also tested for interactive or synergistic effects of age, hypertension and reduced BDNF availability on WM integrity.

\section{MATERIALS AND METHODS PARTICIPANTS}

The participants were screened for history of neurological and psychiatric conditions, head trauma with loss of consciousness, alcohol and drug abuse, diabetes, thyroid problems, and cardiovascular disease (except controlled essential hypertension). Participants were screened for dementia and depression with the MMSE (Folstein et al., 1975) and the Center for Epidemiological Study Depression Scale (CES-D; Radloff, 1977), with cut-offs of 26 and 15, respectively. All participants were strongly right-handed (75\% and above on the Edinburgh Handedness Questionnaire; Oldfield, 1971). Participants provided written informed consent in accord with university and hospital review board guidelines.

The sample was part of a larger sample of 77 adult volunteers (age 19-84, 49 women) who underwent MRI scanning and cognitive testing as described elsewhere (Kennedy and Raz, 2009; Kennedy and Raz, in press). Genetic material was available on 41 Caucasian participants (all of which are included in this study), 25 women and 16 men, $43-81$ years old (mean $64.17 \pm 10.06$ years), and had an average education at college level (mean $16.34 \pm 2.68$ years). Of the 25 women, 17 were in the val and 8 were in the met group, and of the men, 9 were in the val group, and 7 were in the met group. Sample demographic information is presented in Table 1. There were no sex differences in age, CES-D or MMSE scores, systolic or diastolic blood pressure (all $t \leq 1 \mathrm{ns)}$ ). Men attained on average two more years of formal education than women $[t(39)=2.48$, $p<0.02]$. The sample included 17 individuals with hypertension, defined as described below. Only $2(4.9 \%)$ participants smoked tobacco products and $30(73 \%)$ reported exercising regularly. Thus, the participants of this study were healthier and better educated than the general population (American Heart Association, 2004).

\section{GENOMIC ANALYSIS}

DNA isolations and genotyping assays were conducted in the Wayne State University Applied Genomics Technology Center. For genotyping quality control, $10 \%$ direct repeats and DNA sequencing for verification were performed. We used both control DNA and no-template controls, and ran all 5'-nuclease assays on an Applied Biosystems 7900. After isolating DNA from buccal cultures obtained in mouthwash samples, we used a Gentra Autopure LS under the standard buccal cell protocol.

Polymorphism for BDNF val66met (rs6265) was interrogated using Taqman SNP Genotyping assays, with DNA sequencing reactions carried out using the $0.5 \times$ protocol for ABI PRISM BigDye Terminator Cycle Sequencing Ready Reaction Kit (Applied Biosystems). The sequencing extension products, purified with Sephadex, were analyzed on an ABI PRISM 3700 DNA Analyzer using a 50-cm capillary array.

The allelic distribution of the BDNF val66met polymorphism fit the Hardy-Weinberg equilibrium $\left(\chi^{2}=2.05, p=0.15\right)$, with $63 \%$ of participants being val homozygotes $(n=26)$, and $37 \% \mathrm{val} / \mathrm{met}$ heterozygotes $(n=15)$, whereas no participants had the rare met/met genotype. The val/val and the val/met individuals did not differ in age $(p=0.86)$, education level $(p=0.48), \operatorname{MMSE}(p=0.51)$, CES-D $(p=0.17)$ scores, or systolic $(p=0.22)$ or diastolic $(p=0.29)$ blood pressure (see Table 1 for sample demographics by genotype).

\section{BLOOD PRESSURE MEASURES}

Each participant had systolic and diastolic blood pressure measured with an analog mercury sphygmomanometer (Model 12-525; Country Technology, Gays Mills, WI, USA) equipped with a standard brachial cuff (Omron Professional). Participants sat in a comfortable chair in a climate-controlled office. Blood pressure was measured on three separate days, once from each arm, and averaged

Table 1 | Sample demographic information by BDNF genotype and total sample: mean \pm SD.

\begin{tabular}{|c|c|c|c|c|c|c|c|}
\hline Group & $N$ & Age & Edu & MMSE & CES-D & Systolic BP & Diastolic BP \\
\hline val/val & 26 & $63.96 \pm 10.79$ & $16.11 \pm 2.82$ & $28.35 \pm 1.16$ & $3.42 \pm 3.59$ & $127.40 \pm 11.93$ & $74.37 \pm 8.84$ \\
\hline val/met & 15 & $64.53 \pm 8.99$ & $16.73 \pm 2.46$ & $28.60 \pm 1.18$ & $5.33 \pm 5.16$ & $132.65 \pm 14.57$ & $77.08 \pm 5.52$ \\
\hline Total & 41 & $64.17 \pm 10.06$ & $16.34 \pm 2.68$ & $28.44 \pm 1.16$ & $4.12 \pm 4.24$ & $129.32 \pm 13.03$ & $75.36 \pm 7.83$ \\
\hline
\end{tabular}

$N$, sample size; edu, years of education; MMSE, mini-mental status exam; CES-D, center for epidemiological study depression scale; BP, blood pressure mmHg. The groups did not differ significantly on any of the demographic variables (all p-values $>0.17$ ). 
across samples and sessions. Current and prior hypertensive status and medication information was collected from an interview and a comprehensive health questionnaire completed before entrance to the study. Only participants who had controlled hypertension or were normotensive were allowed into the study. Hypertension was operationally defined as systolic blood pressure greater than $140 \mathrm{mmHg}$ and diastolic pressure greater than $90 \mathrm{mmHg}$ (Joint National Committee on Prevention, Detection, Evaluation, and Treatment of High Blood Pressure, 1997). Individuals whose blood pressure exceeded the cutoff were referred to their physician.

\section{MRI PROTOCOL}

MR images were acquired on a 1.5-T Magnetom Sonata scanner (Siemens Medical Systems, Erlangen, Germany). The DTI data were acquired with a single shot echo-planar imaging sequence acquired in the axial plane with six directions, $b=0$ and $1000 \mathrm{~mm}^{2} / \mathrm{s}, 10$ averages, $\mathrm{TE}=97 \mathrm{~ms}, \mathrm{TR}=5400 \mathrm{~ms}$, acquisition matrix $=192 \times 192$, FOV $=345 \mathrm{~mm}$, voxel size $=1.8 \times 1.8 \times 3 \mathrm{~mm}^{3}$. Duration of acquisition was $6.25 \mathrm{~min}$.

\section{DTI processing}

The data were processed with the DTI module of Analyze software (BIR, Mayo Clinic, Rochester, MN, USA). Each DTI scan was first binned into the baseline $(b=0)$ and six gradient encoded volumes (each containing 33 slices) using the Dicom Tool module and these seven separated scans were imported into the DTI module. After the diffusion gradient orientation information was entered for each volume, the data were thresholded to reduce extracerebral noise, the tensor was computed, and individual FA maps were generated.

\section{Region of interest measurement}

Images for manual tracing of regions of interest (ROIs) were displayed on a 21' monitor and on a 21' LCD digitizing tablet (Wacom Cintiq model 21UX; Wacom Inc., Vancouver, WA, USA) and magnified $\times 2$. Each $R O I$ was traced manually with a stylus on the T2weighted $(b=0)$ baseline image for each participant in native space and supplemented with simultaneous side-by-side views from the FA and FA color map images in the same native coordinate space to maximize neuroanatomic validity. The saved ROI was applied to the FA maps and mean and standard deviation FA obtained within each ROI, for each participant separately on three slices, and then averaged across the three slices.

The ROIs were specifically drawn well within the inner portions of the WM regions to minimize the potential of partial voluming effects that can occur in the border voxels at the interface of gray/white and CSF/white boundaries. Test-retest reliability was determined for one operator (Kristen M. Kennedy) by tracing eight images (for each ROI) on two separate occasions, 2 weeks apart. Reliability of mean FA for each ROI was assessed by an intraclass correlation, formula ICC (3) (Shrout and Fleiss, 1979), and exceeded 0.90 (genu ICC3 $=0.91$, splenium ICC3 $=0.99$ ). The target ROIs, the genu and splenium of the corpus callosum, were demarcated as described below.

The operator drew a small ROI on the genu and the splenium (Figure 1), medially-to-laterally on the axial plane, with reference to the sagittal and coronal planes assisted by the OrthoReview function in Analyze ROI module. We took special care to exclude, both

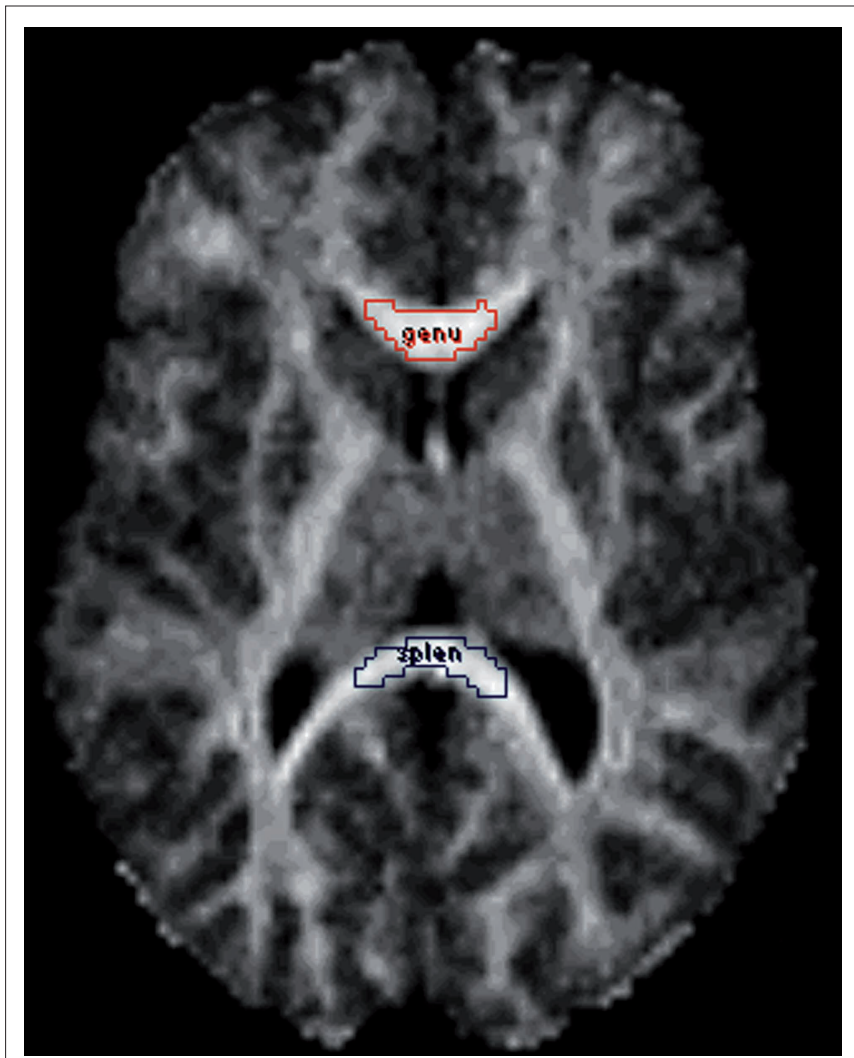

FIGURE 1 | Demarcation of the corpus callosum regions of interest (ROIs): genu (red) and splenium (blue). The ROls are displayed on a fractional anisotropy map.

visually and by monitoring the standard deviations, pixels that could reflect cerebro-spinal fluid from the ventricles. The genu and the splenium were measured on the same three axial slices in which both were optimally visible.

\section{STATISTICAL ANALYSES}

The data were analyzed in the General Linear Model framework with SYSTAT 12 (Systat Software, Inc., Chicago, IL, USA). Age, centered at the sample mean, was a continuous predictor. Sex, hypertension status, and allelic variant of BDNF val66met (val vs. val/met) entered the model simultaneously as categorical predictors. The callosal ROI (genu and splenium) was the repeated measure, and FA was the dependent variable. Second-order interactions among all predictors were also included in the models, but if found nonsignificant $(p>0.15)$ they were deleted from the model to conserve power. All interactions involving repeated measures used $p$-values adjusted by Huynh-Feldt correction factor.

\section{RESULTS}

The analysis revealed a significant main effect of ROI $[F(1$, $35)=44.30, p<0.0001]$, with splenium FA $(0.79 \pm 0.04)$ exceeding that of the genu $(0.74 \pm 0.06)$, and a trend for the main effect of age $F(1,35)=3.95, p=0.055$. None of the other between-subjects main effects reached significance: sex $F<1$ ns; hypertension $F(1$, $35)=1.16, p=0.29$; and $B D N F$ genotype $F<1$ ns. However, 
there was a significant $\mathrm{ROI} \times$ age $\times B D N F$ genotype interaction, $F(1,35)=4.99, p=0.03$, indicating that the magnitude of the age differences in FA varied between the ROIs and depended on $B D N F$ val66met genotype. The interactions age $\times B D N F$ genotype $(F<1)$, ROI $\times \operatorname{sex}(F<1)$, and ROI $\times$ hypertension $(F<1)$ were not significant.

To decompose the $\mathrm{ROI} \times$ age $\times B D N F$ genotype interaction depicted in Figure 2, we regressed regional FA on age for each $B D N F$ met allele group. In the BDNF val66 homozygotes (BDNF 66met-), there was a nonsignificant trend for an age effect in the genu FA $(b=-0.00217 \pm 0.00108 ; t=-2.02, r=-0.38, p=0.055)$, and no age difference in splenium FA $(b=-0.0004 \pm 0.00063 ; t=0.64$, $r=-0.13, p=0.53$ ). In heterozygotes (BDNF 66met carriers), there was also no age effect on genu FA: $b=-0.00154 \pm 0.00173$, $t=-0.90, r=-0.24, p=0.39$; however, a significant decline in splenium FA was observed: $b=-0.00309 \pm 0.00129, t=-2.40$, $r=-0.55, p=0.03$. Removal of an outlier (74-year-old man) did not change the results for genu $(t=-0.24, p=0.81)$ or splenium $(t=-2.43, p=0.03)$. The contribution of nonlinear (quadratic) trends in all four regressions was not significant. Comparison of age slopes of the four regression models revealed that all of the
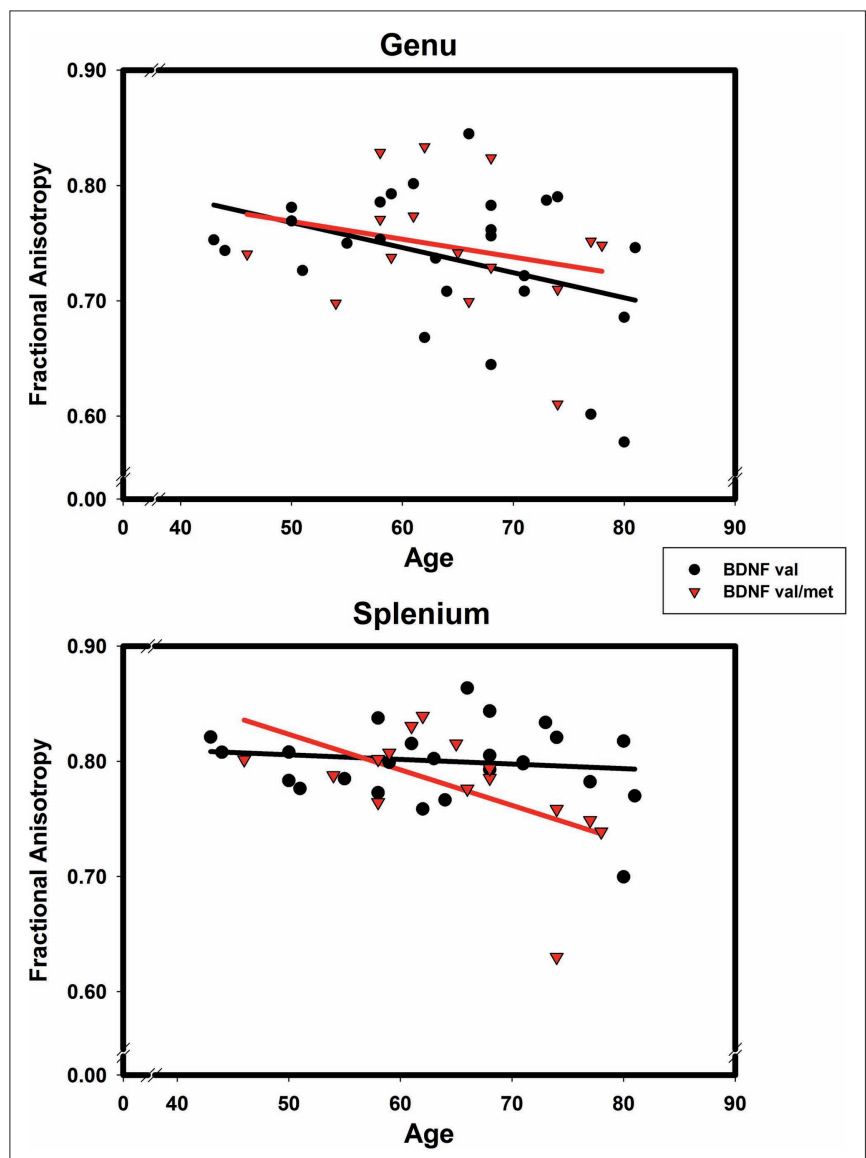

FIGURE 2 |The effects of BDNF 66met allele on age-related differences in fractional anisotropy of genu (upper panel) and splenium (lower panel) of the corpus callosum. Black solid line and circles correspond to val homozygotes; red broken line and triangles correspond to val/met heterozygotes.
$90 \%$ confidence limits except one, overlapped. Only the slope of regression of the splenium FA among the val/val homozygotes was reliably flatter than the rest.

\section{DISCUSSION}

The results of this small-scale investigation show that at least in one region, the splenium of the corpus callosum, age-related reduction in WM integrity depends on variation in a major neurotrophin gene. Only persons who carried a low-activity allele of the BDNF Val66Met polymorphism evidenced age-related decline in FA. Whereas the observed effects of age on the genu FA were unclear, the dependence of age-related differences in the splenium on BDNF genotype was apparent. Age had no effect on splenium FA in BDNF val66 homozygotes and was associated with a significantly lower FA in the splenium of BDNF 66met carriers. There was a nonsignificant trend for the effect of age on the genu FA in the val group. However, examination of the correlations for each ROI and BDNF group suggests that for the genu FA, the strength of association was comparable between groups ( $r=-0.38$ vs. -0.24 ) and the difference in significance reflects low statistical power of the study. In spite of that, this preliminary investigation is, to the best of our knowledge, the first reported finding of $B D N F$ val66met effect on regional WM integrity in healthy aging.

White matter aging is usually more prominent in the anterior (prefrontal white and genu) than posterior (parietal white and splenium) brain regions (Raz et al., 2005, 2007; Sullivan and Pfefferbaum, 2006), whereas in the presence of pathological processes or risk factors, a more generalized pattern involving deterioration of the posterior brain regions is observed as well (Raz et al., 2007). The finding reported here adds the low-activity BDNF met allele to the list of such risk factors. Further, these results are in accord with the report that the posterior region of the CC is under significantly greater genetic control than anterior regions (Pfefferbaum et al., 2001).

Although investigation of relevant polymorphisms is an increasingly popular means for explicating specific components of the observed genetic contribution to brain and cognition (de Geus et al., 2008; Green et al., 2008; Mattay et al., 2008), association studies of specific polymorphisms and WM microstructure are still rare. The three extant studies report a negative influence of ApoE $\varepsilon 4$ on parahippocampal (Nierenberg et al., 2005) and frontal (Bartzokis et al., 2006) WM and on the splenium (Persson et al., 2006) and genu (Bartzokis et al., 2006) in older adults. In young adults, neuroregulin-1 has been found to affect FA in the internal capsule (McIntosh et al., 2008) and the medial frontal WM (Winterer et al., 2008). As mentioned, to date, no association studies examined the effects of BDNF genetic variation on cerebral WM in healthy adults.

Diffusion-derived indices of WM integrity reflect many aspects and components of the WM structure (Song et al., 2002; Davis et al., 2009), and they may be differentially affected by aging. Myelin is a product of metabolically intensive processes (Peters, 2002; Bartzokis, 2004), and BDNF, in its capacity as metabotropic factor and promoter of axonal growth, affects lifespan destiny of the WM. Thus far, BDNF has been implicated in repair and maintenance of the WM in demyelinating disease (Stadelmann et al., 2002; Azoulay et al., 2008), although the role of BDNF val66met in that process is unclear (Weinstock-Guttman et al., 2007). The 
differential vulnerability of the anterior and posterior portions of the corpus callosum may stem from its cytological characteristics. Axon density, degree of myelination, and axonal diameter vary along the anterior-posterior axis of the corpus callosum (Lamantia and Rakic, 1990). The anterior portion is densely populated by small myelinated and unmyelinated axons, whereas the posterior portion contains a higher proportion of large myelinated axons and is the only segment to contain giant axons (i.e., $0.90 \mu \mathrm{m}$ ). The splenium also has the lowest percentage of unmyelinated axons (3.5\%) in the corpus callosum (Lamantia and Rakic, 1990). Given this highly segregated organization, it stands to reason that the segments of the corpus callosum would be differentially sensitive to aging (Aboitiz et al., 1996) and to clinical and genetic risk factors. Because the splenium is the most heavily myelinated part of the corpus callosum, the impact of reduced capacity for axonal repair (e.g., due to dearth of BDNF) may be most apparent there.

Contrary to our hypothesis, we found neither a significant effect of hypertension, nor a joint effect of that vascular risk factor and the genetic variation on WM integrity. The reasons for this are unclear, but may include relatively low statistical power as well as selection of healthier-than-average hypertensive individuals. In addition, this study is limited to a cross-sectional design and derivation of the index of WM integrity from a relatively early version of the DTI sequence. Notably, the lack of significant effects of age

\section{REFERENCES}

Aboitiz, F., Rodrigues, E., Olivares, R., and Zaidel, E. (1996). Age-related changes in fibre composition of the human corpus callosum: sex differences. Neuroreport 7, 1761-1764.

American Heart Association (2004). Heart Disease and Stroke Statistics - 2005 Update. Dallas, TX, American Heart Association.

Ardekani, S., Kumar, A., Bartzokis, G., and Sinha, U. (2007). Exploratory voxelbased analysis of diffusion indices and hemispheric asymmetry in normal aging. Magn. Reson. Imaging 25, 154-167.

Azoulay, D., Urshansky, N., and Karni, A. (2008). Low and dysregulated BDNF secretion from immune cells of MS patients is related to reduced neuroprotection. J. Neuroimmunol. 195, 186-193.

Bartzokis, G. (2004). Age-related myelin breakdown: a developmental model of cognitive decline and Alzheimer's disease. Neurobiol. Aging 25, 5-18.

Bartzokis, G., Lu, P.H., Geschwind, D. H., Edwards, N., Mintz, J., and Cummings, J. L. (2006). Apolipoprotein E genotype and age-related myelin breakdown in healthy individuals: implications for cognitive decline and dementia. Arch. Gen. Psychiatry 63, 63-72.

Bath, K. G., and Lee, F. S. (2006). Variant BDNF (Val66Met) impact on brain structure and function. Cogn. Affect Behav. Neurosci. 6, 79-85.
Binder, D. K., and Scharfman, H. E. (2004). Brain-derived neurotrophic factor. Growth Factors 22, 123-131.

Bueller, J. A., Aftab, M., Sen, S., GomezHassan, D., Burmeister, M., and Zubieta, J. K. (2006). BDNF Val66Met allele is associated with reduced hippocampal volume in healthy subjects. Biol. Psychiatry 59, 812-815.

Chepenik, L. G., Fredericks, C., Papademetris, X., Spencer, L., Lacadie, C., Wang, F., Pittman, B., Duncan, J. S., Staib, L. H., Duman, R. S., Gelernter, J., and Blumberg, H. P. (2009). Effects of the Brain-Derived Neurotrophic Growth Factor Val66Met variation on hippocampus morphology in bipolar disorder. Neuropsychopharmacology 34, 944-951.

Davis, S. W., Dennis, N.A., Buchler, N. G., White, L. E., Madden, D. J., and Cabeza, R. (2009). Assessing the effects of age on long white matter tracts using diffusion tensor tractography. Neuroimage 46, 530-541.

de Geus, E., Goldberg, T., Boomsma, D. I., and Posthuma, D. (2008). Imaging the genetics of brain structure and function. Biol. Psychol. 79, 1-8. Oudkerk, M., Ramos, L. M., van Gijn, J., and Breteler, M. M. (2001). Prevalence of cerebral white matter lesions in elderly people: a population based magnetic resonance imaging study. The Rotterdam Scan de Leeuw, F. E., de Groot, J. C., Achten, E. Heijboer, R., Hofman, A., Jolles, J.,

in the presence of nonsignificant trends in the expected direction can be attributed to the low statistical power and curtailment of age range to middle-aged and older adults. All these limitations are being addressed in the longitudinal study of a larger sample that is currently underway in our laboratory.

\section{CONCLUSION}

The positive effect of homozygosity for the high-activity BDNF val allele on a selected region of the cerebral WM, the splenium of the corpus callosum, suggests that with adequate BDNF availability older adults may benefit from the plasticity and repair mechanisms to maintain healthy aging, whereas carriers of the met allele may be at risk for more widespread WM deterioration. Maintenance of these repair mechanisms in the posterior corpus callosum in older age may be important for the preservation of cognitive functions dependent on interhemispheric transfer via this region - spatial, mnemonic, and visual processing.

\section{ACKNOWLEDGMENTS}

This study was supported in part by National Institutes of Health grants R37 AG-011230 and T32 HS-013819, and by a Dissertation Award from the American Psychological Association. A portion of this paper was presented at the Society for Neuroscience Annual Meeting in November 2008.

Study. J. Neurol. Neurosurg. Psychiatry 70, 9-14.

Egan, M. F., Kojima, M., Callicott, J. H., Goldberg, T. E., Kolachana, B. S. Bertolino, A., Zaitsev, E., Gold, B. Goldman, D., Dean, M., Lu, B., and Weinberger, D. R. (2003). The BDNF val66met polymorphism affects activity-dependent secretion of BDNF and human memory and hippocampal function. Cell 112, 257-269.

Flechsig, P. (1901). Developmentalmyel ogenetic localisation of the cerebral cortex in the human subject. Lancet 19, 1027-1029.

Folstein, M. F., Folstein, S. E., and McHugh, P. R. (1975). 'Mini-mental state'. A practical method for grading the cognitive state of patients for the clinician. J. Psychiat. Res. 12, 189-198.

Green, A. E., Munafò, M. R. Deyoung, C. G., Fossella, J. A., Fan, J., and Gray, J. R. (2008). Using genetic data in cognitive neuroscience: from growing pains to genuine insights. Nat. Rev. Neurosci. 9, 710-720.

Hasan, K. M., Kamali, A., Kramer, L. A. Papanicolaou, A. C., Fletcher, J. M., and Ewing-Cobbs, L. (2008). Diffusion tensor quantification of the human midsagittal corpus callosum subdivisions across the lifespan. Brain Res. 1227, 52-67.

Head, D., Buckner, R. L., Shimony, J. S. Girton, L. E., Akbudak, E., Conturo, T. E., McAvoy, M., Morris, J. C., and Snyder, A.Z. (2004).
Differential vulnerability of anterior white matter in nondemented aging with minimal acceleration in dementia of the Alzheimer type: evidence from diffusion tensor imaging. Cereb. Cortex $14,410-423$.

Hugenschmidt, C. E., Peiffer, A. M., Kraft, R.A., Casanova, R., Deibler, A. R., Burdette, J. H., Maldjian, J. A., and Laurienti, P. J. (2008). Relating imaging indices of white matter integrity and volume in healthy older adults. Cereb. Cortex 18, 433-442.

Irikura, K., Morii, S., Miyasaka, Y., Yamada, M., Tokiwa, K., and Yada, K. (1996). Impaired autoregulation in an experimental model of chronic cerebral hypoperfusion in rats. Stroke 53, 1399-1404.

Joint National Committee on Prevention, Detection, Evaluation, and Treatment of High Blood Pressure (1997). The sixth report of the Joint National Committee on Prevention, Detection, Evaluation, and Treatment of High Blood Pressure. Arch. Intern. Med. 157, 2413-2446.

Katan, M. B. (1986). Apolipoprotein E isoforms, serum cholesterol and cancer. Lancet 327, 507-508.

Kennedy, K. M., and Raz, N. (2009). Aging white matter and cognition: differential effects of regional variations in diffusion properties on memory, executive functions, and speed. Neuropsychologia 7, 916-927.

Kennedy, K. M., and Raz, N. (in press). Pattern of normal age-related 
regional differences in white matter microstructure is modified by vascular risk. Brain Res.

Kochunov, P., Thompson, P. M., Lancaster, J. L., Bartzokis, G., Smith, S., Coyle, T., Royall, D. R., Laird, A., and Fox, P. T. (2007). Relationship between white matter fractional anisotropy and other indices of cerebral health in normal aging: tract-based spatial statistics study of aging. Neuroimage 35, 478-487.

Krabbe, K. S., Nielsen, A. R., KroghMadsen, R., Plomgaard, P., Rasmussen, P., Erikstrup, C., Fischer, C. P., Lindegaard, B., Petersen, A.M., Taudorf, S., Secher, N.H., Pilegaard, H., Bruunsgaard, H., and Pedersen, B. K. (2007). Brain-derived neurotrophic factor (BDNF) and type 2 diabetes. Diabetologia 50, 431-438.

Lamantia, A. S., and Rakic, P. (1990). Cytological and quantitative characteristics of four cerebral commissures in the rhesus monkey. J. Comp. Neurol. 291, 520-537.

Lebrun, B., Bariohay, B., Moyse, E., and Jean, A. (2006). Brain-derived neurotrophic factor BDNF and food intake regulation: a minireview. Auton. Neurosci. 126-127, 30-38.

Lee, T.H., Yang, J. T., Kato, H., and Wu, J. H. (2006). Hypertension downregulates the expression of brain-derived neurotrophic factor in the ischemia-vulnerable hippocampal CA1 and cortical areas after carotid artery occlusion. Brain Res. 1116, 31-38.

Madden, D. J., Spaniol, J., Whiting, W. L., Bucur,B., Provenzale, J. M., Cabeza, R., White, L. E., and Huettel, S. A. (2007). Adult age differences in the functional neuroanatomy of visual attention: a combined fMRI and DTI study. Neurobiol. Aging 28, 459-476.

Mattay, V.S., Goldberg, T.E., Sambataro, F., and Weinberger, D. R. (2008). Neurobiology of cognitive aging: insights from imaging genetics. Biol. Psychol. 79, 9-22.

McIntosh,A.M., Moorhead, T.W., Job, D., Lymer, G. K., Muñoz Maniega, S., McKirdy, J., Sussmann, J.E., Baig, B. J., Bastin, M.E., Porteous, D., Evans, K. L., Johnstone, E. C., Lawrie, S. M., and Hall, J. (2008). The effects of a neuregulin 1 variant on white matter density and integrity. Mol. Psychiatry 13, 1054-1059.

Miyajima, F., Ollier, W., Mayes, A., Jackson, A., Thacker, N., Rabbitt, P., Pendleton, N.,Horan, M., and Payton, A. (2008). Brain-derived neurotrophic factor polymorphism Val66Met influences cognitive abilities in the elderly. Genes Brain Behav. 7, 411-417.

Mochizuki, N., Takagi, N., Kurokawa, K., Onozato, C., Moriyama, Y.,
Tanonaka, K., and Takeo, S. (2008). Injection of neural progenitor cells improved learning and memory dysfunction after cerebral ischemia. Exp. Neurol. 211, 194-202.

Nemoto, K., Ohnishi, T., Mori, T. Moriguchi,Y.,Hashimoto, R.,Asada, T., and Kunugi, H. (2006). The Val66Met polymorphism of the brain-derived neurotrophic factor gene affects agerelated brain morphology. Neurosci. Lett. 397, 25-29.

Nierenberg,J.,Pomara,N.,Hoptman, M. J., Sidtis, J. J., Ardekani, B. A., and Lim, K. O. (2005). Abnormal white matter integrity in healthy apolipoprotein E epsilon4 carriers. Neuroreport 16, 1369-1372.

Nomura, T., Honmou, O., Harada, K., Houkin, K., Hamada, H., and Kocsis, J. D. (2005). I.V. infusion of brain-derived neurotrophic factor gene-modified human mesenchymal stem cells protects against injury in a cerebral ischemia model in adult rat. Neuroscience 136, 161-169.

Oldfield, R. C. (1971). The assessment and analysis of handedness. Neuropsychologia 9, 97-113.

O'Sullivan, M., Jones, D. K.,Summers, P. E., Morris, R. G., Williams, S. C. R., and Markus, H. S. (2001). Evidence for cortical 'disconnection' as a mechanism of age-related cognitive decline. Neurology 57, 632-638.

Persson, J., Lind, J., Larsson, A., Ingvar, M., Cruts, M., Van Broeckhoven, C., Adolfsson, R., Nilsson, L. G., and Nyberg, L. (2006). Altered brain white matter integrity in healthy carriers of the APOE epsilon4 allele: a risk for AD? Neurology 66, 1029-1033.

Peters, A. (2002). Structural changes in the normally aging cerebral cortex of primates. Prog. Brain Res. 136, 455-465.

Pezawas, L., Verchinski, B. A., Mattay, V. S., Callicott, J. H., Kolachana, B. S., Straub, R. E., Egan, M. F., MeyerLindenberg, A., and Weinberger, D. R. (2004). The brain-derived neurotrophic factor val66met polymorphism and variation in human cortical morphology. J. Neurosci. 24, 10099-10102.

Pfefferbaum, A., Adalsteinsson, E., and Sullivan, E.V. (2005). Frontal circuitry degradation marks healthy adult aging: evidence from diffusion tensor imaging. Neuroimage 26, 891-899.

Pfefferbaum, A., Mathalon, D. H., Sullivan, E. V., Rawles, J. M., Zipursky, R. B., and Lim, K. O. (1994). A quantitative magnetic resonance imaging study of changes in brain morphology from infancy to late adulthood. Arch. Neurol. 51, 874-887.

Pfefferbaum, A., Sullivan, E. V., and Carmelli, D. (2001). Genetic regulation of regional microstructure of the corpus callosum in late life. Neuroreport $12,1677-1681$.

Pfefferbaum, A., Sullivan, E. V., Hedehus, M., Lim, K. O., Adalsteinsson, E., and Moseley, M. (2000). Age-related decline in brain white matter anisotropy measured with spatially corrected echo-planar diffusion tensor imaging. Magn. Reson. Med. 44, 259-268.

Pierpaoli, C., and Basser, P. J. (1996). Toward a quantitative assessment of diffusion anisotropy. Magn. Reson. Med. 36, 893-906.

Radloff, L. S. (1977). The CES-D scale: a self-report depression scale for research in the general population. Appl. Psychol. Meas. 1, 385-401.

Raz, N. (2004). The aging brain observed in vivo: differential changes and their modifiers. In Cognitive Neuroscience of Aging: Linking Cognitive and Cerebral Aging, R. Cabeza, L. Nyberg, and D. Park, eds (New York, NY, Oxford University Press), pp. 17-55.

Raz, N., and Kennedy, K. M. (2009). A systems approach to age-related change: neuroanatomical changes, their modifiers, and cognitive correlates. In Imaging the Aging Brain, W. Jagust and M. D'Esposito, eds (New York, NY, Oxford University Press), Chap. 4, pp. 151-268.

Raz, N., Lindenberger, U., Rodrigue, K. M., Kennedy, K. M., Head, D., Williamson, A., Dahle, C., Gerstorf, D., and Acker, J. D. (2005). Regional brain changes in aging healthy adults: general trends, individual differences and modifiers. Cereb. Cortex 15, 1676-1689.

Raz, N., Rodrigue, K. M., Kennedy, K. M. and Acker, J. D. (2007). Vascular health and longitudinal changes in brain and cognition in middle-aged and older adults. Neuropsychology 212 , 149-157.

Raz, N., Rodrigue, K. M., Kennedy, K. M. and Land, S. (2009). Genetic and vascular modifiers of age-sensitive cognitive skills: effects of COMT, BDNF, ApoE and hypertension. Neuropsychology 23, 105-116.

Salat, D. H., Tuch, D. S., Greve, D. N., van der, Kouwe, A. J. W., Hevelone, N. D., Zaleta, A. K., Rosen, B. R., Fischl, B., Corkin, S., Rosas, H.D., and Dale, A. M (2005).Age-related alterations in white matter microstructure measured by diffusion tensor imaging. Neurobiol. Aging 26, 1215-1227.

Schäbitz, W. R., Steigleder, T., CooperKuhn, C. M., Schwab, S., Sommer, C., Schneider, A., and Kuhn, H. G. (2007). Intravenous brain-derived neurotrophic factor enhances poststroke sensorimotor recovery and stimulates neurogenesis. Stroke 38, 2165-2172.
Shrout, P. E., and Fleiss, J. L. (1979). Intraclass correlations: uses in assessing raters reliability. Psychol. Bull. 86, 420-428.

Sohrabji, F., and Lewis, D. K. (2006). Estrogen-BDNF interactions: implications for neurodegenerative diseases. Front Neuroendocrinol 27, 404-414. doi: 10.1016/j.yfrne.2006.09.003.

Song, S. K., Sun, S. W., Ramsbottom, M. J., Chang, C., Russell, J., and Cross, A. H. (2002). Dysmyelination revealed through MRI as increased radial (but unchanged axial) diffusion of water. Neuroimage 17, 1429-1436.

Sowell, E. R., Thompson, P. M. Holmes, C. J., Jernigan, T. L., and Toga, A. W. (1999). In vivo evidence for post-adolescent brain maturation in frontal and striatal regions. Nat. Neurosci 2, 859-861.

Stadelmann, C., Kerschensteiner, M., Misgeld, T., Brück, W., Hohlfeld, R., and Lassmann, H. (2002). BDNF and gp145trkB in multiple sclerosis brain lesions: neuroprotective interactions between immune and neuronal cells? Brain 125, 75-85.

Stadlbauer, A., Salomonowitz, E., Strunk, G.,Hammen, T., Ganslandt, O. (2008). Age-related degradation in the central nervous system: assessment with diffusion tensor imaging and quantitative fiber tracking. Radiology 247, 179-188.

Sublette, M. E., Baca-Garcia, E., Parsey, R. V., Oquendo, M. A., Rodrigues, S. M., Galfalvy, H., Huang, Y.Y.,Arango, V., and Mann, J. J. (2008). Effect of BDNF val66met polymorphism on age-related amygdala volume changes in healthy subjects. Prog. Neuropsychopharmacol. Biol. Psychiatry 32, 1652-1655.

Sullivan, E. V., Adalsteinsson, E., Hedehus, M., Ju, C., Moseley, M., Lim, K. O., and Pfefferbaum, A. (2001). Equivalent disruption of regional white matter microstructure in ageing healthy men and women. Neuroreport 12, 99-104.

Sullivan, E. V., and Pfefferbaum, A. (2006). Diffusion tensor imaging and aging. Neurosci. Biobehav. Rev. 30, 749-761.

Szeszko, P. R., Lipsky, R., Mentschel, C., Robinson, D., Gunduz-Bruce, H., Sevy, S., Ashtari, M., Napolitano, B. Bilder, R. M., Kane, J. M., Goldman, D. and Malhotra, A. K. (2005). Brainderived neurotrophic factor val66met polymorphism and volume of the hippocampal formation. Mol. Psychiatry 10, 631-636.

Takahashi, T., Suzuki, M., Tsunoda, M., Kawamura, Y., Takahashi, N., Tsuneki, H., Kawasaki, Y., Zhou, S. Y., Kobayashi, S., Sasaoka, T., Seto, H., 
Kurachi, M., and Ozaki, N. (2008). Association between the brainderived neurotrophic factor Val66Met polymorphism and brain morphology in a Japanese sample of schizophrenia and healthy comparisons. Neurosci. Lett. 4351, 34-39.

Weinstock-Guttman, B., Zivadinov, R. Tamaño-Blanco,M.,Abdelrahman, N., Badgett, D., Durfee, J., Hussein, S., Feichter, J., Patrick, K., Benedict, R., and Ramanathan, M. (2007). Immune cell BDNF secretion is associated with white matter volume in multiple sclerosis. J. Neuroimmunol. 188, 167-174.

Winterer, G., Konrad, A., Vucurevic, G., Musso, F., Stoeter, P., and Dahmen, N. (2008). Association of $5^{\prime}$ end neuregulin-1 (NRG1) gene variation with subcortical medial frontal microstructure in humans. Neuroimage 40, 712-718.

Yanamoto, H., Xue, J. H., Miyamoto, S., Nagata, I., Nakano, Y., Murao, K., and Kikuchi, H. (2004). Spreading depression induces long-lasting brain protection against infarcted lesion development via BDNF genedependent mechanism. Brain Res. 1019, 178-188.

Conflict of Interest Statement: The authors declare that the research was conducted in the absence of any commercial or financial relationships that could be construed as a potential conflict of interest.

Received: 23 May 2009; paperpending published: 08 June 2009; accepted: 31 July 2009; published online: 20 August 2009.
Citation: Kennedy KM, Rodrigue KM, Land SJ and Raz N (2009) BDNF val66met polymorphism influences age differences in microstructure of the corpus callosum. Front. Hum. Neurosci. 3:19. doi: 10.3389/neuro.09.019.2009

Copyright (c) 2009 Kennedy, Rodrigue, Land and Raz. This is an open-access article subject to an exclusive license agreement between the authors and the Frontiers Research Foundation, which permits unrestricted use, distribution, and reproduction in any medium, provided the original authors and source are credited. 